EESTI NSV TEADUSTE AKADEEMIA TOIMETISED. GEOLOOGIA

ИЗВЕСТИЯ АКАДЕМИИ НАУК ЭСТОНСКОП ССР. ГЕОЛОГИЯ

PROCEEDINGS OF THE ACADEMY OF SCIENCES OF THE ESTONIAN SSR. GEOLOGY

1984, 33, 2

удК $550.42: 546(474.2)$

В. КЛЕИН, В. ПУУРА, М. КРЫЛОВА, К. ОРЛОВСКАЯ

\title{
ОСОБЕННОСТИ РАСПРЕДЕЛЕНИЯ МИКРОКОМПОНЕНТОВ В МАГНЕТИТАХ ПОРОД КРИСТАЛЛИЧЕСКОГО ФУНДАМЕНТА ЭСТОНИИ
}

Среди рассеянных рудных минералов магматических и метаморфических пород кристаллического фундамента Эстонии наиболее часто встречается магнетит. Возможность использования микрокомпонентного состава этого минерала в качестве индикатора условий формирования и формационной принадлежности определенных типов пород доказана многими исследователями.

Нами сделана попытка охарактеризовать специфические особенности распределения микрокомпонентов в магнетите кристаллических пород фундамента Эстонии и высказать на этой основе некоторые предположения о генезисе пород. Мономинеральные фракции магнетита выделены из образцов метаморфических пород и связанных с ними гранитоидов (мигматит-гранитов и чарнокитов) (всего 74 пробы, табл. 1 и 2), а также интрузивных пород (14 проб, табл. 3), отобранных из керна скважин, пробуренных в различных структурных зонах кристаллического фундамента Эстонии (Кристаллический..., 1983). Количественный спектральный анализ 11 элементов этих проб выполнен в спектральной лаборатории Института геологии и геохронологии докембрия АН СССР. Для характеристики распределения отдельных компонентов между магнетитом и другими минералами породы в качестве примера использованы также результаты химического анализа биотитов и амфиболов (Центральная лаборатория Управления геологии ЭССР) тех же проб, однако как сами результаты анализа биотита, так и их обобщения заслуживают специального рассмотрения.

Магнетиты метаморфических пород сгруппированы в соответствии с принятыми ранее схемами расчленения и районирования метаморфических комплексов (Коппельмаа и др., 1978; Кристаллический..., 1983). Почти во всех исследованных пробах с магнетитом ассоциирует ильменит, реже гематит. Ильменит образует структуры распада твердого раствора или же присутствует в породе в виде отдельных самостоятельных зерен. Очень часто наблюдаются обе эти формы ильменита. Поэтому дополнительного деления магнетитов на группы по характеру ассоциирующего ильменита не проводили. Присутствие ильменита или гематита указывает на равновесное состояние магнетита и минеральной ассоциации породы.

Для определения влияния валового состава породы на содержание микрокомпонентов в магнетите пробы разбиты на 3 основные группы: 1) метабазиты; 2) глиноземистые и биотитовые гнейсы (метапелиты); 3) граниты и чарнокиты. Отчетливо видно, что магнетиты глиноземистых и биотитовых гнейсов содержат меньше микрокомпонентов, чем магнетиты метабазитов (табл. 1). Исключение составляют распределение $\mathrm{Cu}$, которое не дает такой прямой связи, и поведение $\mathrm{V}$ 


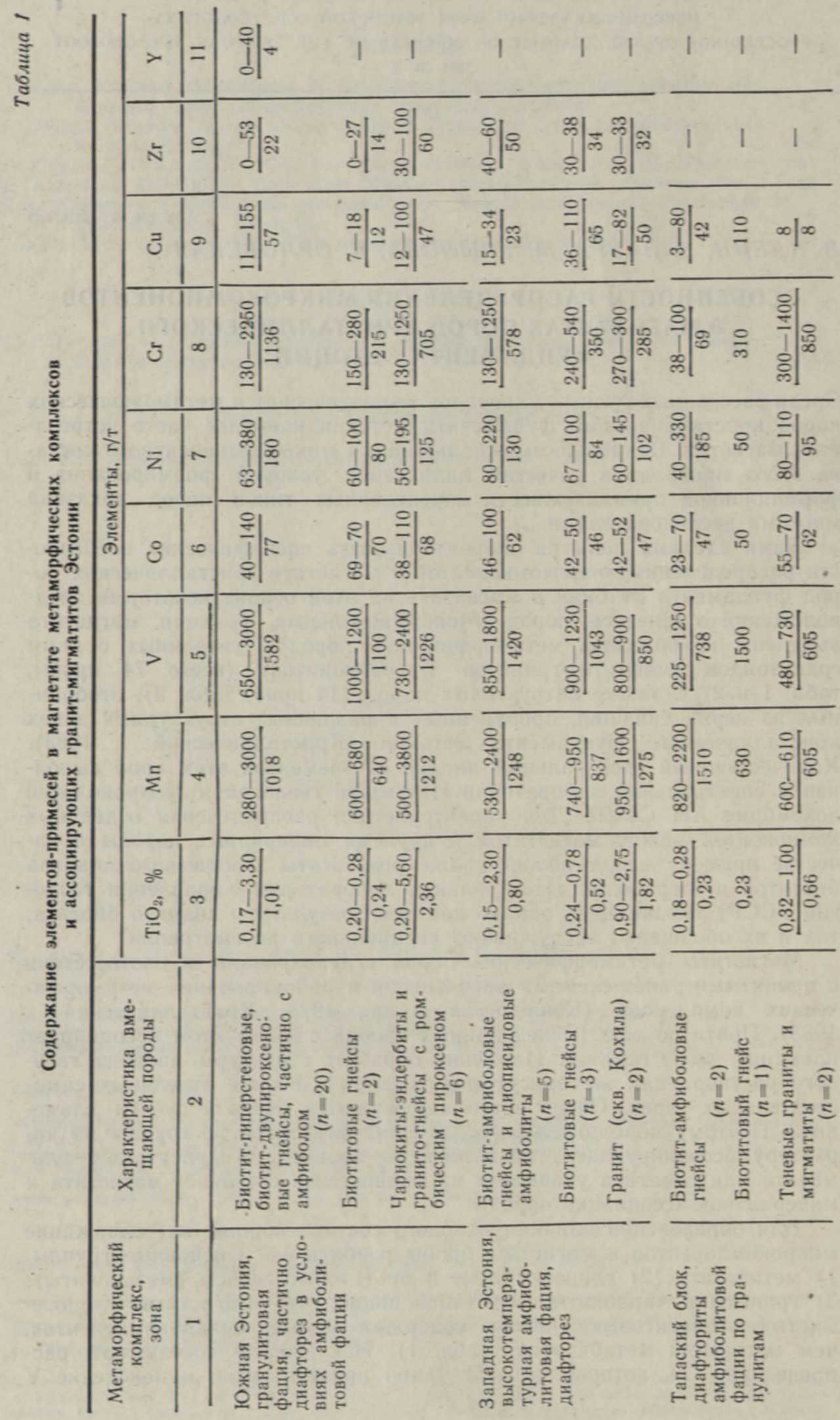


ह

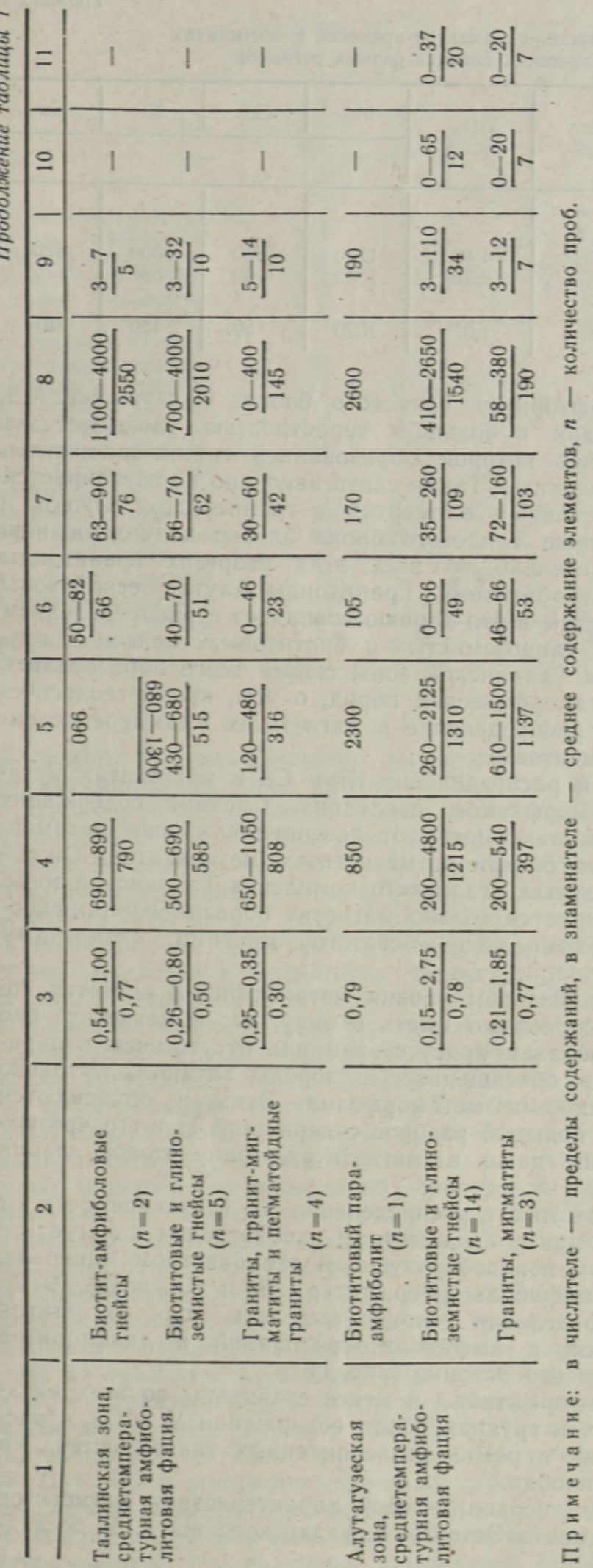


Среднее содержание элементов-примесей в магнетитах кристаллических сланцев разных регионов

\begin{tabular}{l|c|r|r|r|r|r}
\hline \multirow{2}{*}{ Регион } & $\begin{array}{c}\text { Чнсло } \\
\text { проб }\end{array}$ & $\begin{array}{r}\mathrm{TiO}_{2} \\
\text { вес. } \%\end{array}$ & $\mathrm{Mn}$ & $\mathrm{Co}$ & $\mathrm{Ni}$ & $\mathrm{Cu}$ \\
\cline { 3 - 6 } & & & & & & \\
\hline
\end{tabular}

и $\mathrm{Cr}$ в магнетитах диафторитов Тапаского блока. Содержание $\mathrm{Mn}$, $\mathrm{Co}, \mathrm{V}$ и $\mathrm{Ni}$ в гранитондах с большой вероятностью указывает на исходную породу, за счет которой образовались гранит-мигматиты, теневые граниты или чарнокиты. Такая связь наглядно иллюстрируется тем, что содержание названных элементов в гранитоидах Южной и Западной Эстонии, а также Тапаского блока близко их содержанию в метабазитах, и действительно, во всех этих разрезах гранитоиды ассоцинруют только с метабазитами. Гранитоиды Алутагузеской зоны развивались по метапелитам и это хорошо совпадает с распределением элементов в магнетитах глиноземистых и биотитовых гнейсов и гранитов. Гранит-мигматиты Таллинской зоны скорее всего образовались за счет обеих групп метаморфических пород, о чем, кроме геологических данных, говорит и распределение в магнетитах вышеперечисленных информативных элементов.

Довольно интересно и распределение $\mathrm{Ni}$ и $\mathrm{Cu}$ в магнетитах метабазитов в связи с метаморфизмом последних. Средние содержания $\mathrm{Ni}$ и $\mathrm{Cu}$ повышаются в зависимости от повышения уровня метаморфизма. Их концентрация больше в магнетитах метабазитов Южной Эстонии, меньше в магнетитах ягалаского комплекса Таллинской зоны. Этому правилу не подчиняется только магнетит образца параамфиболита алутагузеского комплекса, богатого многими элементами (табл. 1).

Общепризнанным индикатором уровня метаморфизма является содержание Ті. Однако необходимо иметь в виду, что в магнетите оно определяется главным образом присутствием или отсутствием в парагенезисе ильменита, т. е. обогащенностью породы титаном, и только во вторую очередь условиями метаморфизма. Этим и объясняются известный в литературе большой разброс содержаний $\mathrm{Ti}$ и его чрезвычайно низкие содержания даже в магнетитах гранулитовой фации метаморфизма.

Более закономерно выглядит распределение $\mathrm{Ti}$ (в зависимости от условий метаморфизма) при его совместном рассмотрении в магнетите и в каком-нибудь другом породообразующем темноцветном минерале, обычно в бнотите или амфиболе (Ферштатер, 1973; Крылова, 1977). На основе такого распределения условно выделены поля магнетитов метабазитов гранулитовой и амфиболитовой фаций и диафторитов кристаллического фундамента Эстонии (рис. 1).

Относительно малоинформативны и менее стабильны во всех метаморфических комплексах и группах пород содержания V и Co, а распределение $\mathrm{Cr}$ не входит в рамки вышеописанных зависимостей. $\mathrm{Nb}$ обнаружен лишь в трех пробах.

Ниже приведен пример сравнительной характеристики магнетитов кристаллического фундамента Эстонии и Алданского щита. В послед- 
Рис. 1. Распределение $\mathrm{TiO}_{2}$ в метабазитах: a) между магнетитом (Mt) и бнотитом (Bi), б) между магнетитом и роговой обманкой; амфнбол $(\mathrm{Am})$. I предположительно поле гранулитовой, II высокотемпературной амфиболитовой, III низкотемпературной амфнболитовой (включая диафториты) фаций. Минералы пород: $I$ гранулитовой фации Южной Эстонии, 2 амфиболитовой фации Западной Эстонии, 3 диафторитов Тапаского блока, 4 амфиболитовой фации Таллинской зоны.
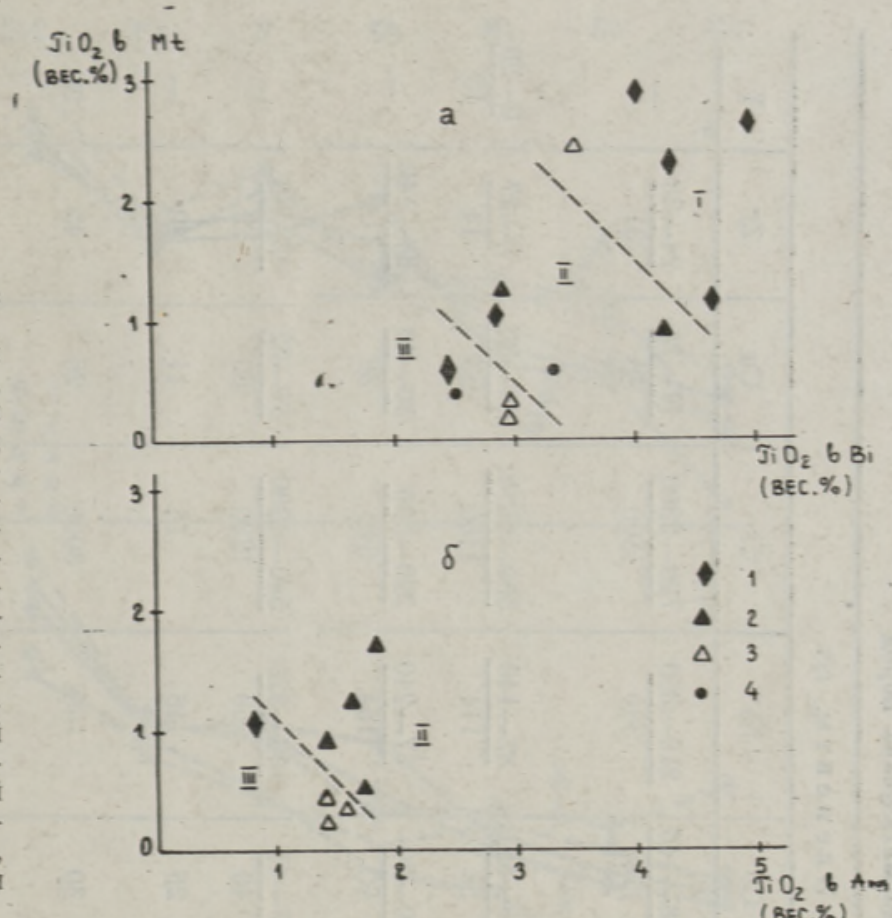

нем регионе проанализированы магнетиты сходных по составу и степени метаморфизма пород (Крылова, Галибин, 1977).

Содержание большинства малых элементов в магнетитах пород группы метабазитов гранулитовой и амфиболитовой фаций Алданского щита более высоко, чем в породах соответствующих фаций кристаллического фундамента Эстонии (рис. 2). Закономерность распределе, ния содержаний $\mathrm{Cr}$ и $\mathrm{V}$ обратная. В магнетитах гранитоидов отмеченная тенденция не так четко выражена, но и здесь содержание определенных элементов в магнетитах пород Алдана заметно выше. На диаграмме распределения соотношений $\mathrm{Cu}$ и $\mathrm{Ni}$ четко обозначено различие состава магнетитов двух регионов (рис. $3 a, 6)$.

Выяснение причин этого различия требует более тонкого изучения состава вмещающих пород, их формационной принадлежности и истории формирования. В частности, может оказаться перспективным сравнительное изучение распределения микроэлементов в сосуществующих магнетитах и силикатных минералах однотипных пород (т. е. однотипных минеральных ассоциаций) сопоставляемых структур. Сопоставление магнетитов гранулитового комплекса Южной Әстонии с магнетитами кристаллических сланцев Южной и центральной части Алданского щита (последние четко отличаются между собой по давлению метаморфизма) (Крылова, 1977) наводит на мысль, что низкое содержание микроэлементов в магнетите гранулитов Эстонии (табл. 2) обусловлено метаморфизмом более низкого давления.

По 14 анализам магнетитов магматических пород можно предварительно охарактеризовать распределение микроэлементов с учетом состава вмещающих пород (табл. 3). Магнетиты пород основного состава обогащены титаном, марганцем, кобальтом и никелем. Содержание $\mathrm{Ti}$ и $\mathrm{Mn}$ в магнетите офитовых габбро массива Сигула Таллинской зоны свекофеннид значительно выше, чем в амфиболизированных габброидах архейских комплексов. Присутствие Ті скорее всего объясняется высокой температурой образования породы, а $\mathrm{Mn}$-- eго reo- 


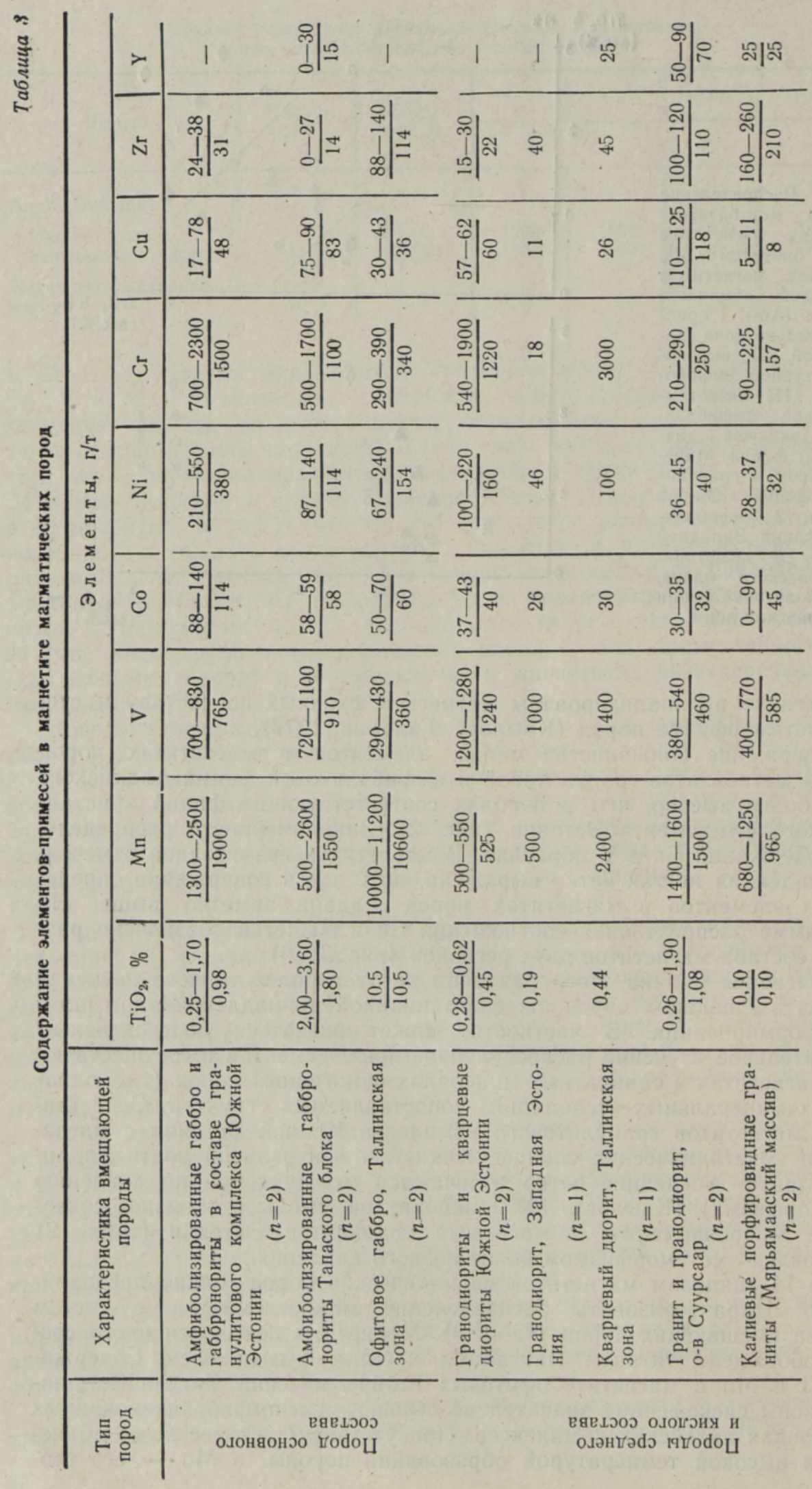




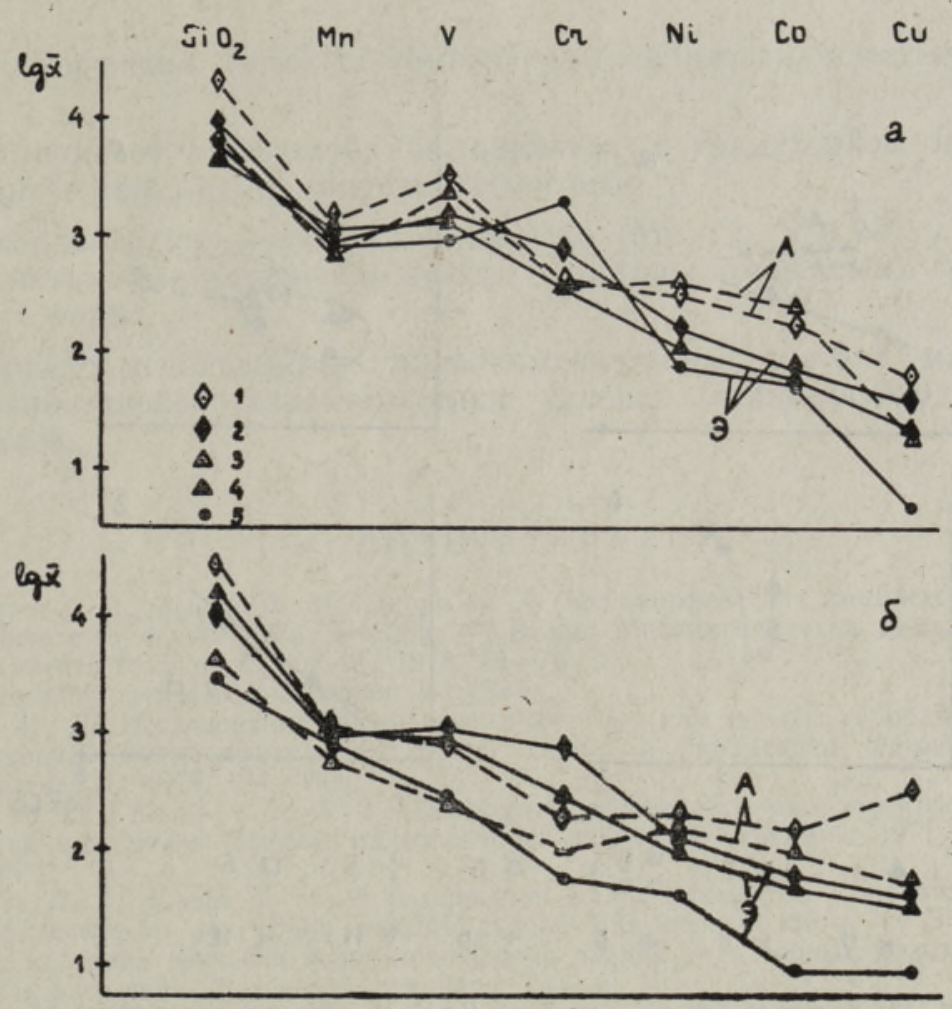

Рис. 2. Содержание элементов-примесей ( $\lg \bar{x}-$ средние логарифмы содержаний в $\mathrm{r} / \mathrm{T}): a$ ) в магнетитах метабазитов, б) в магнетитах гранитоидов кристаллического фундамента Эстонии (Э) и Алданского щита (А). Вмещающие породы: 1 гранулитовой фации Алданского щита, 2 гранулитовой фации Южной Әстонии, 3 амфиболитовой фации Алданского щита, 4 амфиболитовой фации Западной Эстонии, 5 амфиболитовой фации Таллинской зоны.

химической особенностью, так как в аналогичных высокотемпературных магнетитах (Фоминых, 1976) столь высокого содержания не отмечено̇. Этот магнетит содержит в заметном количестве и $\mathrm{Zn}(2000$ г/т), что, видимо, подтверждает ранее сделанный вывод о положительной специализации массива Сигула на Zn (Петерселль, Клейн, 1976).

Весьма сходны магнетиты кварцевых диоритов Южной Әстонии и Таллинскөй зоны, но содержание $\mathrm{Mn}$ и $\mathrm{Cr}$ в магнетите этих пород Таллинской зоны заметно выше, а $\mathrm{Co}, \mathrm{Ni}$ и $\mathrm{Cu}$ ниже. Особый интерес представляет то, что магнетит из гранодиорита Западной Эстонии (массив Виртсу) характеризуется очень низким содержанием всех элементов и при этом близок по составу магнетитам калиевых гранитов Мярьямааского массива.

Различие в составе магнетитов габброидов (особенно габброидов внутри гранулитовых комплексов, рис. 3в) фундамента Эстонии и Алданского щита аналогично различию состава магнетитов метаморфических пород. Видимо, содержание $\mathrm{Ni}$ и $\mathrm{Cu}$ в магнетитах средних и кислых пород может находиться в зависимости от температуры образования этих пород (рис. 32).,Небезынтересно, что по среднему содержанию микроэлементов в магнетите, кварцевые диориты Юго-Восточной Финляндии (Haapala, Ojanperä, 1972) очень близки к аналогичным породам Таллинской зоны.

Предварительно выявленные закономерности распределения микроэлементов базируются в первую очередь на сопоставлении средних 


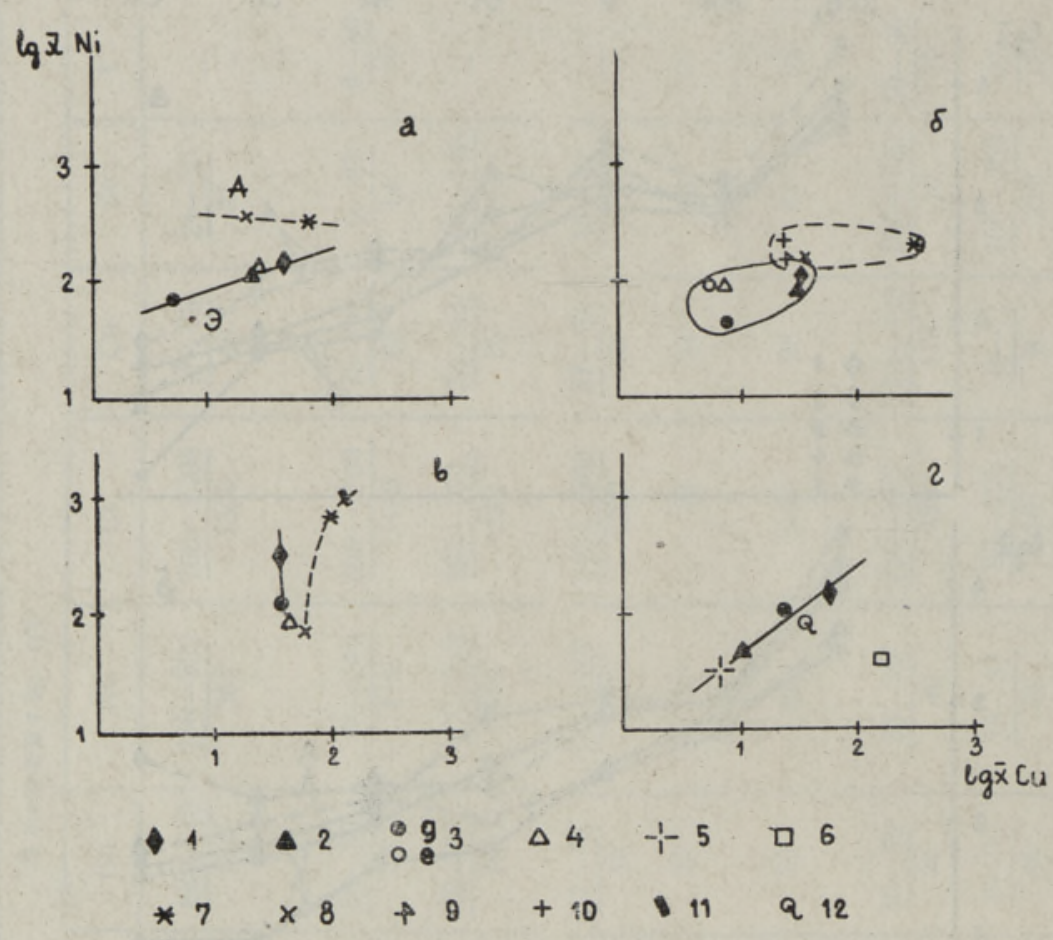

Рнс. 3. Соотношения никеля и меди $(\lg \bar{x}-$ средние логарифмы содержаний, г/т): a) в магнетитах метабазитов, б) гранит-мигматитов и чарнокитов, в) магматическнх пород основного состава, 2) среднего и кислого составов кристаллического фундамента Эстонии (Э), Алданского щита (A) и Южной Финляндии. Вмещающие породы: 1 гранулитовая фация Южной Эстонии, 2 амфиболитовая фация Западной Эстонии, 3 амфиболитовая фация Таллинской $(\partial)$ и Алутагузеской $(\varkappa)$ зон, 4 диафториты Тапаского блока, 5 калиевые порфировидные граниты, 6 граниты о-ва Суурсаар; $7-11$ Алданский щит: 7 гранулитовая фация, 8 амфиболитовая фация, 9 пегматиты гранулитовой фации, 10 пегматиты амфиболитовой фации, 11 «древние дайки» основного состава; 12 кварцевые диориты р-на Миккели Юго-Восточной Финляндии.

содержаний по относительно малочисленным выборкам проб. Большой разброс содержаний в отдельных группах пород (см. табл. 1 и 3 ) по крайней мере частично объясняется уже известными причинами: например, диафторическими изменениями гранулитовых и высокотемпературных амфиболитовых комплексов и т. д. Значит, при дальнейших исследованиях возможна более детальная группировка образцов пород, позволяющая снизить разброс содержаний. Однако уже выявленные закономерности весьма удовлетворительно согласуются с известными особенностями строения и развития изученных объектов фундамента Эстонии, чем подтверждается перспективность дальнейшего изучения геохимии магнетита как широкораспространенного минерального индикатора генезиса кристаллических пород.

\section{Выводы}

1. При изучении первичной природы пород, условий их метаморфизма и ультраметаморфизма наиболее информативно сравнительное изучение магнетита и сосуществующих с ним минералов по группам пород сходного валового состава.

2. Ряд элементов, особенно $\mathrm{Ti}, \mathrm{Ni}, \mathrm{Cu}$, является индикаторами усло- 
вий метаморфизма, а также температуры образования магматических пород.

3. В отличие от магнетитов метапелитов и гранитоидов магнетиты метабазитов обогащены микрокомпонентами.

4. По концентрации некоторых элементов (Mn, Co, V и $\mathrm{Ni}$ ) в магнетитах мигматит-гранитов можно судить о составе замещаемых гранитами исходных пород.

5. Возможно использование микрокомпонентного состава магнетитов для сравнительной характеристики условий метаморфизма разных комплексов.

\section{Л ИТ Р Р А У Р А}

Коппельмаа X. Я., Клейн В. М., Пуура В. А. Метаморфические комплексы кристаллического фундамента Эстонии. - В кн.: Метаморфические комплексы фундамента Русской плиты. Л., 1978, 43-76.

Кристаллический фундамент Эстонии. М., 1983.

Крылова М. Д. Исследование рассеянных элементов для оценки термодинамических условнй метаморфизма. - В кн.: Термо- и барометрия метаморфических пород. Л., 1977, 174-183.

Крылова М. Д., Галибин В. А. Геохимические особенности акщессорного магнетита как показатель условий минералообразования. - Геохимия, 1977, 10, 15431551.

Петерселль В. Х., Клейн В. М. О содержании малых элементов в мономинеральном магнетите из докембрия южного склона Балтийского щита. - В кн,: Опыт и методика изучения форм нахождения элементов в горных породах и ореолах рассеяния. Материалы семинара. Таллин, 1976, 17-19.

Феритатер $\Gamma$. Б. Распределение титана и натрия между минералами гранитоидов как геологический термометр. - Геохимия, $1973,1,74-83$.

Фоминых $B . \Gamma$. Температуры образования титаномагнетитовых концентраций по ильменит-магнетитовому геотермометру на примере Урала. - В кн.: Проблемы биминеральной геотермобарометрни. Свердловск, 1976, 58-69.

Haapala, I., Ojanperä, P. Magnetite and ilmenite from some Finnish rocks. - Bull. Geol. Soc. Finl., 1972, 44, 13-20.

\section{Институт геологии}

Академии наук Эстонской ССР

Институт геологии и геохронологии

докембрия Академии наук СССР

\section{Поступила в редакцию} $5 / \mathrm{V} 1983$

\section{KLEIN, V. PUURA, M. KROLOVA, K. ORLOVSKAJA \\ MIKROKOMPONENTIDE JAOTUMISE ISEARASUSED EESTI ALUSKORRAKIVIMITE MAGNETIIDIS}

Kvantitatiivse spektraalanalüüsi abil on uuritud elementide ( $\mathrm{Ti}, \mathrm{Mn}, \mathrm{V}, \mathrm{Co}, \mathrm{Ni}, \mathrm{Cr}, \mathrm{Cu}$, $\mathrm{Zn}$ jt.) sisaldust erineva koostise ja päritoluga moonde- ja magmakivimite hajumagnetiidis. On leitud, et mikroelementide sisaldus, eriti aga nende jaotumine erinevate mineraalide (magnetiidi, biotiidi, amfibooli jt.) vahel sõltub moondekivimites metamorfismi rōhust ja temperatuurist, tardkivimite puhul aga geneesi iseärasustest.

\section{KLEIN, V. PUURA, M. KRYLOVA, K. ORLOVSKAYA \\ PECULIARITIES OF THE DISTRIBUTION OF MICROCOMPONENTS IN THE MAGNETITE OF THE ESTONIAN BASEMENT ROCKS}

The content of $\mathrm{Ti}, \mathrm{Mn}, \mathrm{V}, \mathrm{Co}, \mathrm{Ni}, \mathrm{Cr}, \mathrm{Cu}, \mathrm{Zn}$ a. o. in dispersed magnetite of metamorphic and magma rocks with different composition and origin has been investigated with the help of the quantitative spectral analysis. It has been found that the content of the microelements, especially their distribution in different minerals (magnetite, biotite, amphibole a. o.), depends on the pressure and temperature of the metamorphism in metamorphic rocks, and on the peculiarities of the genesis in magma rocks. 